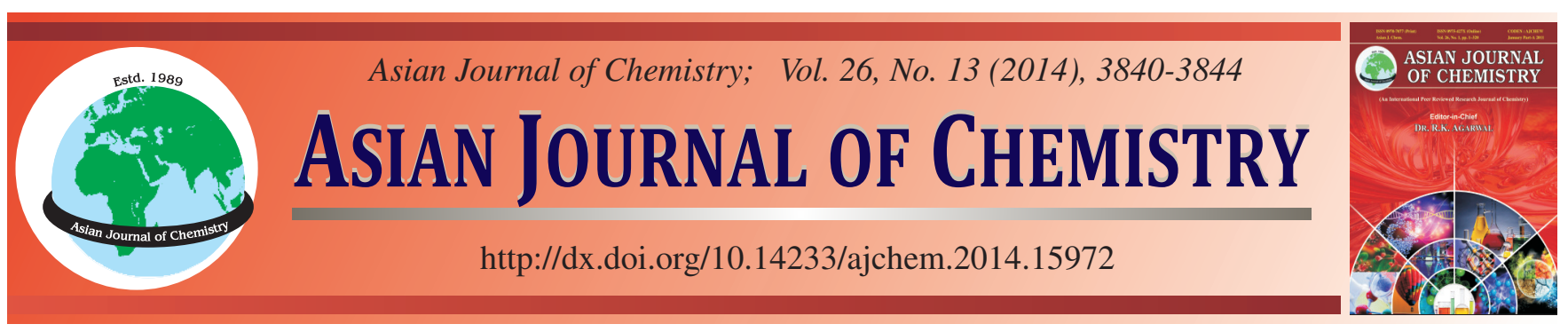

\title{
Effect of Moisture Content on Foaming Behaviour of Poly(vinyl alcohol) During Thermal Foaming Process
}

\author{
H. SHI ${ }^{1}$, Q. WANG ${ }^{2, *}$, L. $\mathrm{LI}^{2}$ and W.B. $\mathrm{MENG}^{3}$
}

\begin{abstract}
' College of Materials and Chemistry \& Chemical Engineering, Chengdu University of Technology, Chengdu 610059, P.R. China ${ }^{2}$ State Key Laboratory of Polymer Materials Engineering (Sichuan University), Polymer Research Institute of Sichuan University, Chengdu 610065, P.R. China

${ }^{3}$ College of Energy Resources, Chengdu University of Technology, Chengdu 610059, P.R. China
\end{abstract}

*Corresponding author: Tel/Fax: +86 28 85405133; E-mail: haoshi@cdut.edu.cn

\begin{abstract}
A polar poly(vinyl alcohol) foam was studied as a function of water content by thermal processing method in present study. The effect of moisture on the melting behaviour of poly(vinyl alcohol) as well as the mechanism of cell nucleation and bubble growth were investigated. The results showed that the water in modified poly(vinyl alcohol) could act as plasticizer to realize the thermal processing of poly(vinyl alcohol) at the early plasticization stage and then volatilize into bubbles in poly(vinyl alcohol) matrix as the blowing agent at the subsequent foaming stage. With the increase of the initial water content, more blowing agent diffused from poly(vinyl alcohol) matrix into the cells due to the increased pressure drop $(\Delta \mathrm{Pw})$, leading to the bubble expansion and the decrease of the apparent density of poly(vinyl alcohol) foam. When the initial water content was $22.7 \mathrm{wt} \%$ and the foaming temperature was $180{ }^{\circ} \mathrm{C}$, poly(vinyl alcohol) foam with relatively uniform cell structure could be obtained.
\end{abstract}

Keywords: Poly(vinyl alcohol) foam, Water blowing agent, Thermal processing, Foaming mechanism.

\section{INTRODUCTION}

Polymer foam is a special polymer composite with gas as filler. It has been applied in many fields such as cushion materials, thermal insulation materials, sound-proof materials and absorbing materials for the properties of light weight, thermal and electrical insulation, big surface area, etc ${ }^{1-3}$. However, most polymer foams, e.g. polyethylene, polypropylene and polystyrene, are non-polar, limiting their applications in some absorption and separation fields.

Poly(vinyl alcohol) is a polar polymer with excellent mechanical properties, heat-resistance properties and absorption properties. So poly(vinyl alcohol) resin has been used to produce various products like fibers, films and adhesives. Poly(vinyl alcohol) foam is of great interest, because it is polar, multi-functional, environmental-friendly and is likely to be used as biodegradable packaging materials, absorbents for heavy metal ion and carriers of wound dressing, etc ${ }^{4-6}$.

Great efforts have been made to develop poly(vinyl alcohol) foam, but the conventional methods are almost based on aqueous solution and gel due to the close melting point and decomposition temperature of poly(vinyl alcohol), which makes the thermal processing of poly(vinyl alcohol) very difficult. For example, Höfelmnn et al. ${ }^{7}$ prepared modified poly(vinyl alcohol) sponge from the aqueous solution of poly(vinyl alcohol) by introducing the strong inorganic acid and formaldehyde as catalyst and cross-linker respectively. By aqueous method, Zhu prepared poly(vinyl alcohol) foam for medical health using glyoxal and sodium carbonate as crosslinker and chemical blowing agent respectively ${ }^{8}$. Delvaux et al. ${ }^{9}$ prepared the light weight mineral poly(vinyl alcohol) foam by dissolving phosphoric acid, wollastonite and calcium carbonate salt in poly(vinyl alcohol) solution. The blowing agent, carbon dioxide, in this system was produced through the chemical reaction between phosphoric acid and calcium carbonate salt. However, all above wet processes had the disadvantages of long production period (over $5 \mathrm{~h}$ ), high cost and the residual of chemical blowing agent and cross-linker, thus restricted the commercial applications of poly(vinyl alcohol) foam. Freeze-drying or freeze thaw techniques for the foaming of poly(vinyl alcohol) gel were also comprehensively studied. Lozinsky et al. ${ }^{10,11}$ prepared foamed poly(vinyl alcohol) cryogels through freeze-thaw-induced gel formation and studied the effect of low-molecular-weight admixture on the foaming, as well as the effects of surfactants on the properties and structure of gas-filled poly(vinyl alcohol) cryogels. Smith et al. ${ }^{12}$ developed 
poly (vinyl alcohol) and poly(acrylic acid) (PAA) based cryofoam for potential wound healing applications. The results showed that the different concentrations of PVA/PAA affected the thermal transitions of the cryogels/cryofoams, which might be applied in drug delivery system.

Thermal foaming is undoubtedly a simple, efficient and environmental-friendly technology to prepare poly(vinyl alcohol) foam. Based on molecular complexation and plasticization, our research group has obtained the thermal processing window for poly(vinyl alcohol) by adopting an amidocontaning compound with complementary structure to poly(vinyl alcohol), together with water, to weaken the inter- and intra-hydrogen bonding among the hydroxyl groups of poly(vinyl alcohol), confine its crystallization, depress its melting point and increase its decomposition temperature ${ }^{13,14}$. It should be noted that water is an important part of the invented modifier for poly (vinyl alcohol) and takes the key role in the realization of the thermal processing of poly(vinyl alcohol). Moreover, water is a kind of low-cost, environmental-friendly, nonflammable, non-toxic and clean blowing agent and has been practically used in the preparation of polymer foams, such as starch foam, polystyrene foam, plastic/wood composites foam and thermoplastic elastics foam, etc. ${ }^{15-20}$, among which the fine dispersion of water is still a challenge due to the weak or non-polarity of the matrix. But for our hydrophilic poly(vinyl alcohol) system, water can disperse in poly(vinyl alcohol) at the molecular level due to the strong interactions between water molecules and the hydroxyl groups of poly(vinyl alcohol), making it possible to form uniformly foam.

Based on our invented thermal processing technology of poly(vinyl alcohol $)^{13}$ and taking the advantage of the multifunctions of water, poly(vinyl alcohol) foam with uniform cell structure was successfully produced by thermal extrusion using water as both plasticizer and physical blowing agent ${ }^{21,22}$. In this paper, we further systematically studied the effects of the thermal processing parameters including initial water content and foaming temperature on the foaming of poly(vinyl alcohol) and discussed the mechanism of cell nucleation and growth.

\section{EXPERIMENTAL}

Poly(vinyl alcohol)1799 (polymerization degree:1750 \pm 50 , hydrolysis degree: $99 \mathrm{~mol} \%$ ) was purchased from the Sichuan Vinylon Works, SINOPEC (China). The modified poly(vinyl alcohol) was prepared according to the pre-literature $^{13}$. Deionized water was used throughout the experiment.

The moisture content of modified poly(vinyl alcohol) was prepared by adding a certain amount of water and then letting it completely seeping into poly(vinyl alcohol) at ambient temperature in a sealed container. The water content in modified poly(vinyl alcohol) pellets was 19.7, 22.7, 25.5, 28.2 and 32.9 wt $\%$, respectively.

A fixed amount of the modified poly(vinyl alcohol) was first placed into a foursquare mold and then loaded in a hot press at the set temperature and clamping force and heated for a certain period. After that, the clamping force of hot press was immediately released to form pressure difference to make modified poly(vinyl alcohol) foamed. At last, the mold was quickly taken out and quenched down to the room temperature for removing the poly(vinyl alcohol) foam from the mold. The set temperature was $160,170,180,190$ and $200{ }^{\circ} \mathrm{C}$, respectively.

\section{Characterizations}

Differential scanning calorimetry (DSC): A NETZSCH - TA 204(German) instrument was used to measure the melting behaviour of the modified poly(vinyl alcohol). About $6 \mathrm{mg}$ sample was sealed in differential scanning calorimetry stainless steel pans with the torque of $3.5 \mathrm{~N} \mathrm{~m}$ in order that the water in the modified poly(vinyl alcohol) can't volatilize from the pan and the measurements of samples were performed by heating from ambient temperature to $250{ }^{\circ} \mathrm{C}$ at a heating rate of 10 ${ }^{\circ} \mathrm{C} /$ min under nitrogen atmosphere.

Scanning electron microscope (SEM) observation: The cellular morphology of poly(vinyl alcohol) foam was observed on an Inspect (FEI, Japan) scanning electron microscope Instrument. The samples were first freeze-fractured and then sputtered through gold coating.

Pressure drop measurement: The vapor pressure and foaming temperature in modified poly(vinyl alcohol) was measured by a digital transducer with both pressure and temperature sensor equipped in the cavity of the mold. Pressure drop was the difference between the measured vapor pressure and the atmospheric pressure. The accuracies of the pressure sensor and temperature sensor were $\pm 0.01 \mathrm{MPa}$ and $\pm 0.1{ }^{\circ} \mathrm{C}$, respectively.

Foam characterization: The mean cell size and cell density were characterized according to the method of Kumar and $\mathrm{Suh}^{23}$. The mean cell size was obtained from scanning electron microscope photos and the cell density $\left(\mathrm{N}_{\mathrm{f}}\right)$ and the number of the cells per cubic centimeters of the foam was calculated by Eq. $(1)^{23}$ :

$$
\mathrm{N}_{\mathrm{f}}=\left[\frac{\mathrm{nM}^{2}}{\mathrm{~A}}\right]^{3 / 2}
$$

where $\mathrm{n}$ is the number of the cells observed from scanning electron microscope photos, $\mathrm{A}$ is the area of the photos $\left(\mathrm{cm}^{2}\right)$ and $\mathrm{M}$ is the magnification factor.

The apparent density of poly(vinyl alcohol) foam was measured by weighing a sample and calculating its volume. Five samples were selected to obtain the average. Expansion ratio of poly(vinyl alcohol) foam was calculated using the density ratio of unfoamed material to the foamed.

The tested samples of poly(vinyl alcohol) foam were stored in sealed containers at $22{ }^{\circ} \mathrm{C}$ and with $50 \%$ relative humidity for one week before test.

\section{RESULTS AND DISCUSSION}

Ascribing to the extremely close melting point and decomposition temperature of poly(vinyl alcohol), thermal processing of poly(vinyl alcohol) has always been a challenge worldwide. The usual method to realize the thermal processing of poly(vinyl alcohol) is to decrease its melting point or increase its decomposition temperature by adding some plasticizers $^{13,24}$.

Water was reported a best plasticizer for poly(vinyl alcohol). In present water plasticized poly(vinyl alcohol) systems, the 
addition of water weakened the intra- and inter-molecular hydrogen bonding of poly(vinyl alcohol) by forming new hydrogen bonding with its hydroxyl groups and expanded the free volume of poly(vinyl alcohol) as well as confined its crystallization, thus reducing its melting point. The more the water content was, the bigger the plasticizing effect of water on poly(vinyl alcohol) and the more the melting point of poly(vinyl alcohol) decreased. Fig. 1 showed the DSC heating curves of the modified poly(vinyl alcohol) with differential water content. In order to effectively prevent the evaporation of water from poly(vinyl alcohol) matrix and exactly measure the melting point of modified poly(vinyl alcohol), the highpressure stainless steel pan was used. Obviously, with the increase of water content, the melting temperature $\left(\mathrm{T}_{\mathrm{m}}\right)$ of the modified poly(vinyl alcohol) continuingly decreased. When water content was $9.1 \mathrm{wt}$. \% , the $\mathrm{T}_{\mathrm{m}}$ of the modified poly(vinyl alcohol) was reduced to about $185^{\circ} \mathrm{C}$ and was further reduced to about $145^{\circ} \mathrm{C}$ with 22.7 wt. $\%$ water content. The decrease of the melting point of poly(vinyl alcohol) provided the possibility for the thermal foaming of poly(vinyl alcohol).

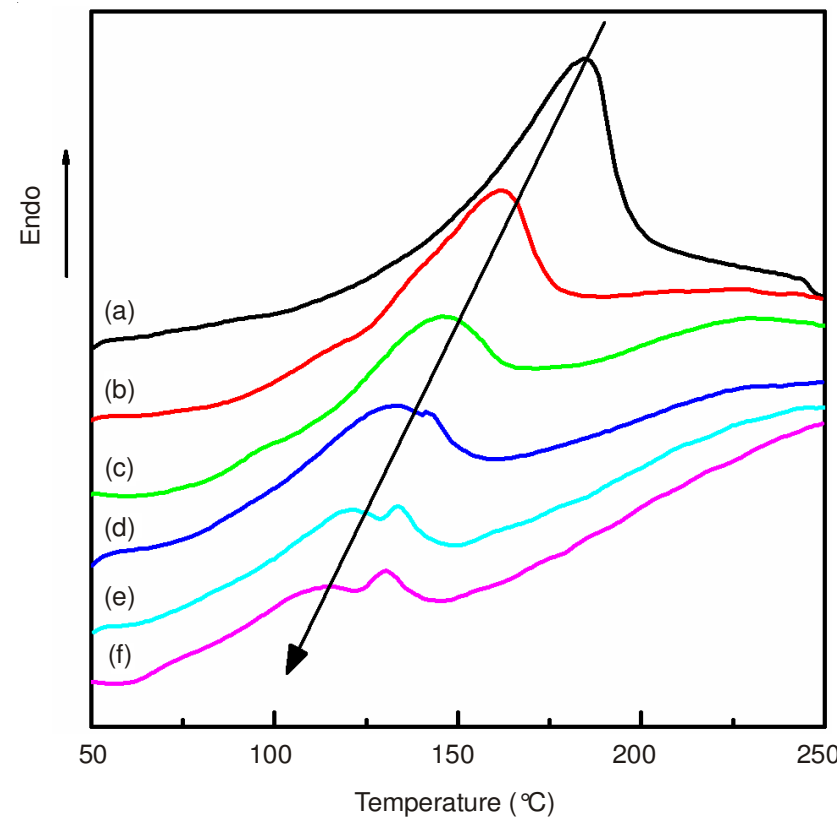

Fig. 1. DSC heating curves of the modified poly(vinyl alcohol) (a) $9.1 \mathrm{wt}$ $\%$, (b) 16.7 wt. $\%$, (c) 22.7 wt. \%, (d) 28.6 , wt. \%, (e) $33.3 \%$ wt. \% (f) 37.5 wt. $\%$

Effect of moisture content on foaming properties of poly(vinyl alcohol) foam: As well known, the blowing agent was mainly consumed in the following three aspects during the foaming process, i.e. bubbles forming, diffusing and resting in polymer matrix. In our research systems, the bubbles mainly formed during the evaporation of water, so moisture content, which was directly related to the amount of the evaporated water when foaming temperature was fixed, was the important factor to be discussed.

Fig. 2 presented the effect of initial water content on the expansion ratio and the apparent density of poly(vinyl alcohol) foam at the foaming temperature of $180{ }^{\circ} \mathrm{C}$. Obviously, the expansion ratio of poly(vinyl alcohol) increased with the increase of initial water content and reached the maximum when water content was $22.7 \mathrm{wt} \%$, i.e. 5.5 , then decreased with the further increase of the initial water content. Contrarily, the apparent density of poly(vinyl alcohol) foam first decreased with the increase of the initial water content and got to the lowest when water content was $22.7 \mathrm{wt} \%$, i.e. $130 \mathrm{~kg} / \mathrm{m}^{3}$, then increased to $300 \mathrm{~kg} / \mathrm{m}^{3}$ when water content further increased to $32.9 \mathrm{wt} \%$ due to the collapse of the bubbles resulted from the excessive vaporization and the depressed melt strength.

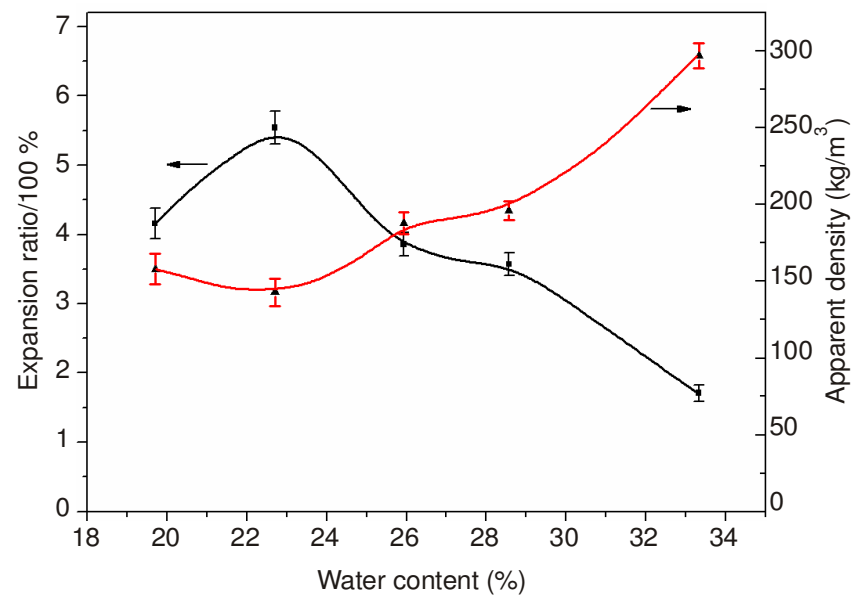

Fig. 2. Effect of initial water content on the expansion of poly(vinyl alcohol) (foaming temperature: $180^{\circ} \mathrm{C}$ )

Fig. 3 showed the cell morphology of poly(vinyl alcohol) foams with different initial water content formed at the fixed temperature of $180{ }^{\circ} \mathrm{C}$. Apparently, poly(vinyl alcohol) foam with the more homogeneous cell structure was obtained with $22.7 \mathrm{wt} \%$ initial water content in modified poly(vinyl alcohol). At low initial water content (19.7 wt \%), the swelled water steam was limited in the melts and the distribution of cell sizes was wide due to the high melt strength of modified poly(vinyl alcohol) (Fig. 3a), while the initial water content increased to 28.2 wt $\%$, the vapor pressure in system could be promoted but the melt strength was not enough to sustain the expanded bubbles, thus deteriorating the cell structure. This phenomenon became more serious when the initial water content further increased to $32.9 \mathrm{wt} \%$ ascribing to the excessive plasticizing effect of water, which largely reduced the viscoelasticity of the modified poly(vinyl alcohol) and caused the coalescence and collapse of the bubbles. Only when initial water content was $22.7 \mathrm{wt} \%$, the melt strength of the modified poly(vinyl alcohol) was suitable for both the bubbles' nucleation and growth.

Foaming mechanism: For the modified poly(vinyl alcohol) foaming systems, the driving force for bubble nucleation and growth was the pressure drop between the atmospheric pressure and the vapor pressure, which was mainly determined by the evaporation of water. Fig. 4 showed the variation of the vapor pressure under different initial water content when the volume of foaming mold cavity and temperature kept constant. Obviously, the increase of initial water content accelerated the water evaporation, thus enhancing the vapor pressure in the sealed cavity and leading up to the higher pressure drop for foaming. 


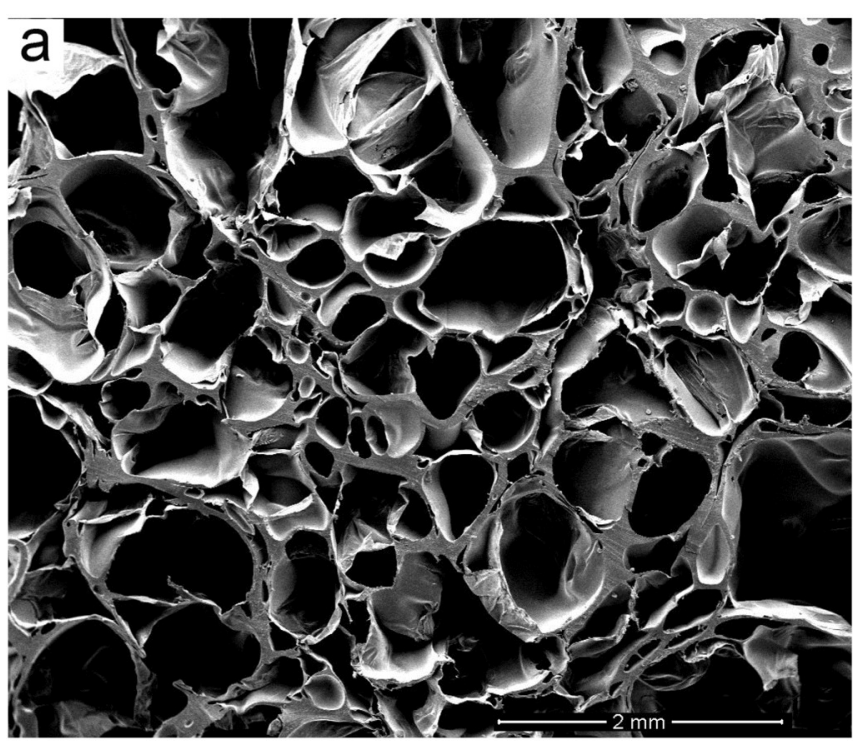

(a)

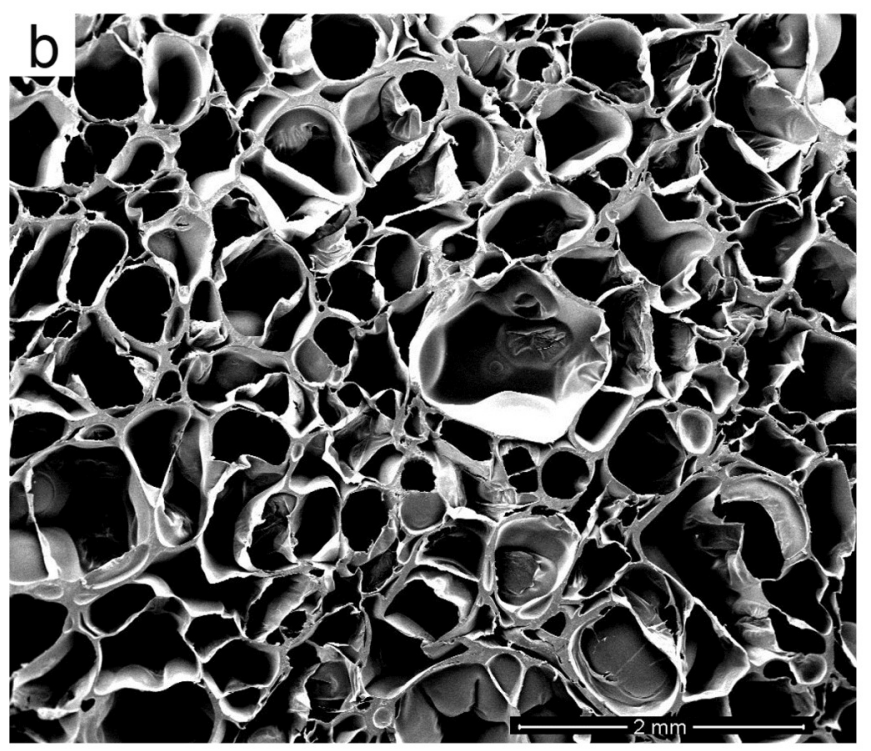

(c)

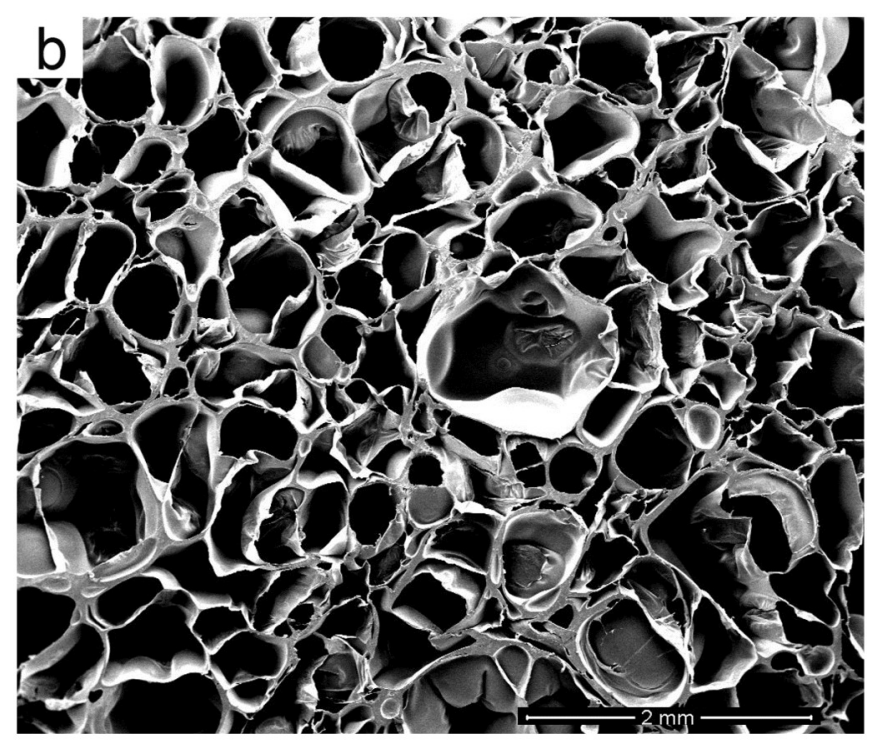

(b)

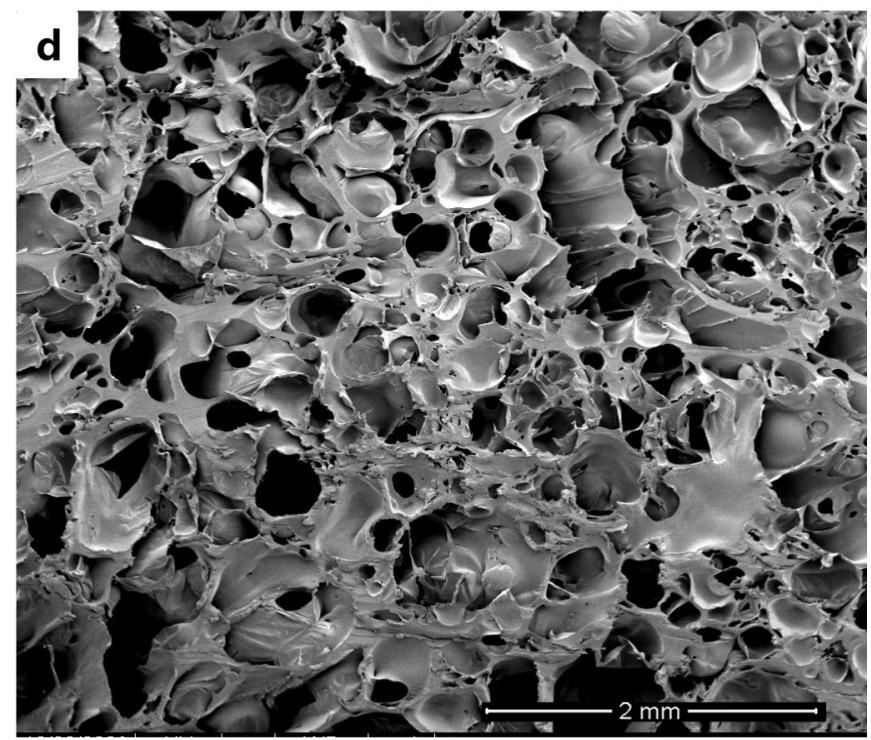

(d)

Fig. 3. Effect of initial water content on the cell morphology of poly(vinyl alcohol) foams (a) $19.7 \mathrm{wt} \%$, (b) $22.7 \mathrm{wt} \%$, (c) $28.2 \mathrm{wt} \%$, (d) 32.9 wt $\left.\%, \mathrm{~T}=180^{\circ} \mathrm{C}, \mathrm{X} 50\right)$

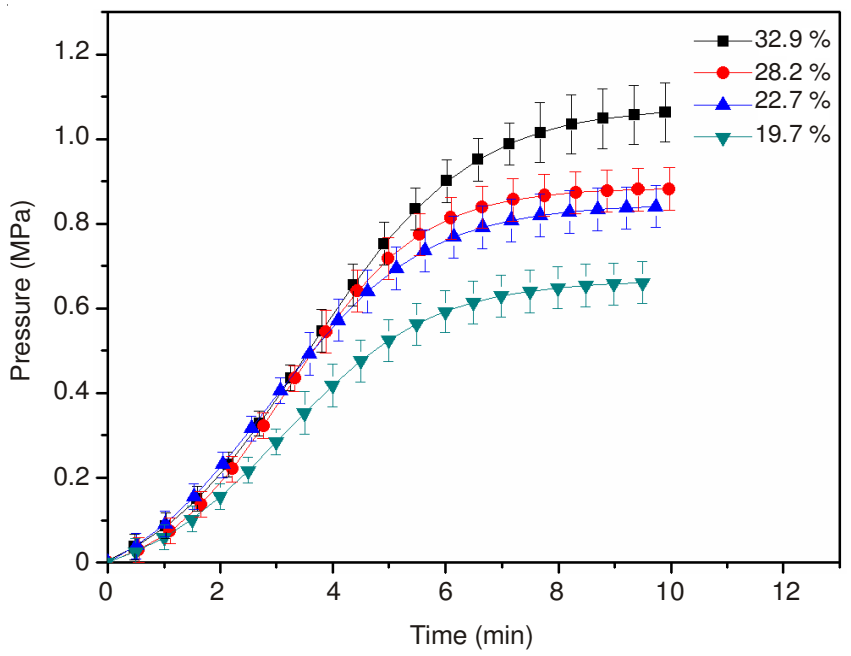

Fig. 4. Effects of initial water content on the vapor pressure (foaming temperature: $180{ }^{\circ} \mathrm{C}$ )
According to the classical nucleation theory, the pressure drop usually determined the cell size and cell density of the foams ${ }^{25,26}$. Usually, the increase of the pressure drop facilitated the nucleation and the growth of the bubbles and induced the formation of the foam with the high nucleation density and small cell size ${ }^{27}$. However, the effect of pressure drop induced by initial water content on the cell size and cell density in this study, which was shown in Fig. 5, didn't fully conform to the classical nucleation theory. In water plasticizing poly(vinyl alcohol) system, with the increase of initial water content, more water would evaporate to enhance the vapor pressure, which surely led to the high pressure drop and was beneficial for the expansion of poly(vinyl alcohol) matrix. But when foaming temperature was fixed, the initial water content influenced not only the pressure drop but also the melt strength of poly(vinyl alcohol) matrix. Besides as the blowing agent, a part of water also acted as the plasticizer during the foaming processing. 


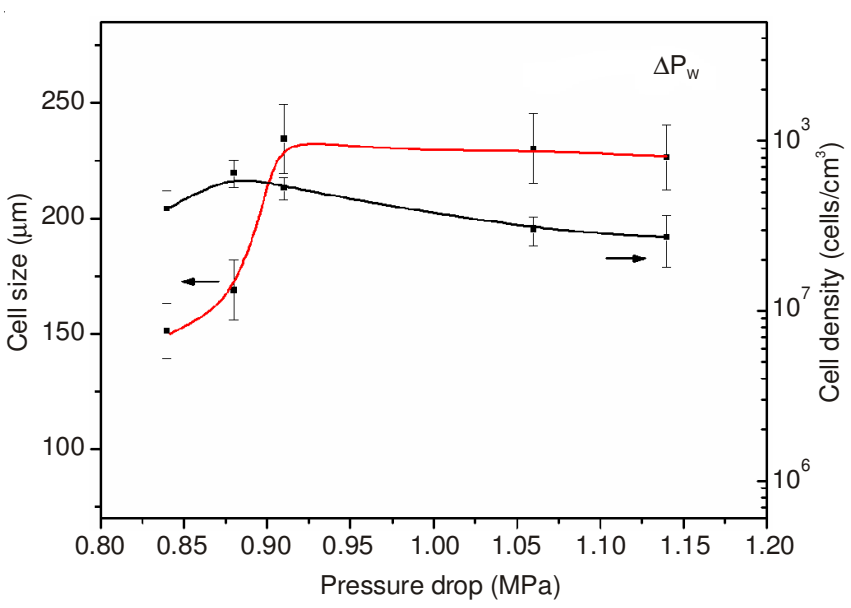

Fig. 5. Effect of pressure drop induced by variation of initial water content on the cell size and cell density of poly(vinyl alcohol) foam (foaming temperature: $180{ }^{\circ} \mathrm{C}$ )

High initial water content also meant the excess residual water in the foaming system, which would decrease the melt strength of poly(vinyl alcohol) matrix and result in the coalescence and deterioration of the bubbles. In the optimal condition, poly(vinyl alcohol) foam with $170 \mu \mathrm{m}$ cell size and $6.5 \times 10^{7}$ cell $/ \mathrm{cm}^{3}$ cell density was obtained.

\section{Conclusion}

In this paper, a novel thermal processing technology for preparing poly(vinyl alcohol) foams using water as both plasticizer and physical blowing agent was reported and the effects of moisture content on the cell morphology of poly(vinyl alcohol) foam as well as the mechanism of cell nucleation and bubble growth were investigated. The results showed that initial water content was the governing parameter for the nucleation, growth and stability of the bubbles. The increase in initial water content was favorable to the expansion of the foam, but when a large amount of water was involved, the volume expansion ratio of poly(vinyl alcohol) foam was reduced due to the vigorous coalescence of the bubbles. According to the analysis of the effect of pressure drop induced by initial water content on the cell morphologies of poly(vinyl alcohol) foams, increment of the pressure drop facilitated the nucleation and growth of the bubbles. But the contraction of the bubbles occurred at over high saturation pressure because the low melt strength of modified poly(vinyl alcohol) couldn't maintain the growth of the bubbles. The optimum cell structure of poly(vinyl alcohol) foam with the cell size $170 \mu \mathrm{m}$ and cell density $6.5 \times 10^{7} \mathrm{cell} / \mathrm{cm}^{3}$ respectively was obtained when initial water content was $22.7 \mathrm{wt} \%$ at the foaming temperature of $180{ }^{\circ} \mathrm{C}$.

\section{ACKNOWLEDGEMENTS}

The authors expressesed their thanks to (1) the Open Fund (PLC201106) of State Key Laboratory of Oil and Gas Reservoir Geology and Exploitation (Chengdu University of Technology); (2) the National Natural Science Foundation of China (50833003, 50903056); (3) the Natural Science Foundation Education Department of Sichuan Province (13ZB0061); (4) the Open Fund of Mineral Resources Chemistry Key Laboratory of Sichuan Higher Education Institutions for financial supports throughout this work. We also expressed our gratitude to Prof. Wenguang $\mathrm{Li}$ for assistance with the digital pressure transducer and pressure profile analysis.

\section{REFERENCES}

1. N.J. Mills, Polymer Foams Handbook: Engineering and Biomechanics Applications and Design Guide, Butterworth-Heinemann Publisher (2007).

2. B.G. Kim and D.G. Lee, J. Mater. Process. Technol., 201, 716 (2008).

3. H.S. Tsay and F.H. Yeh, Appl. Acoust., 69, 778 (2008).

4. F.L. Marten, US Patent 4675360 (1987).

5. M.S. Timmers, N. Graafland, A.T. Bernards, R.G.H.H. Nelissen, J.T. van Dissel and G.N. Jukema, Wound Repair Regen., 17, 278 (2009).

6. X. Wang, Y.S. Chung, W.S. Lyoo and B.G. Min, Polym. Int., 55, 1230 (2006).

7. H. Höfelmnn, R. Braum and H.K. Karl, US Patent 3190843 (1965).

8. T. Q. Zhu, China Patent CN 1095387A (1994).

9. P. Delvaux, N. Lesmerises and D. Poisson, US Patent 5360771 (1994).

10. V.I. Lozinsky and L.G. Damshkaln, J. Appl. Polym. Sci., 82, 1609 (2001).

11. V.I. Lozinsky, L.G. Damshkaln, I.N. Kurochkin and I.I. Kurochkin, Colloid J., 67, 589 (2005).

12. T.J. Smith, J.E. Kennedy and C.L. Higginbotham, J. Mater. Sci. Mater. Med., 20, 1193 (2009).

13. N. Chen, L. Li and Q. Wang, Plast. Rub. Compos., 36, 283 (2007).

14. Q. Wang, L. Li, N. Chen, China Patent CN 100,339,519C (2007).

15. H.A. Pushpadass, G.S. Babu, R.W. Weber and M.A. Hanna, Packag. Technol. Soc., 21, 171 (2008).

16. J.C. Schuber and E.C. LeDuc, US Patent 4455272 (1984).

17. J.Y. Cha, D.S. Chung, P.A. Seib, R.A. Flores and M.A. Hanna, Ind. Crops Prod., 14, 23 (2001).

18. O. Deseke, J. Meyke and A. Pfeiffer, US Patent 5567370 (1996).

19. J. Pallay, P. Kelemen, H. Berghmans and D. Van Dommelen, Macromol. Mater. Eng., 275, 18 (2000).

20. L.M. Matuana and F. Mengeloglu, J. Vinyl Addit. Technol., 8, 264 (2002).

21. X.B. Peng, L. Li. and Q. Wang, Chin. Plast. Ind., 36, 33 (2008) (in Chinese).

22. Q. Wang, L. Li and H. Shi, China Patent ZL 200710049955.6 (2008).

23. V. Kumar and N.P. Suh, Polym. Eng. Sci., 30, 1323 (1990).

24. C.A. Lin and T.H. Ku, J. Mater. Process. Technol., 200, 331 (2008).

25. J.H. Han and C. Dae Han, Polym. Sci. Polym. Phys., 28, 711 (1990).

26. J.S. Colton and N.P. Suh, Polym. Eng. Sci., 27, 500 (1987).

27. K.A. Arora, A.J. Lesser and P.J. Mccarthy, Macromolecules, 31, 4614 (1998). 